\title{
Craft (Ing) Locations: A Study of Locations of Luxury Brands and Exploration of its Implications for the Handloom Sector in NCR, India
}

\author{
Anupam Kapoor ${ }^{1}$, Nandita Abraham ${ }^{2}$ and Ajit Kumar Khare ${ }^{3 *}$ \\ ${ }^{1}$ Research Scholar, National Institute of Fashion Technology, India \\ ${ }^{2}$ CEO, Pearl Academy of Fashion, India \\ ${ }^{3}$ Department of Fashion Technology, India \\ *Corresponding author: Ajit Kumar Khare, Professor, Department of Fashion Technology, Mumbai, India

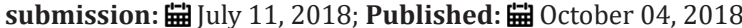

Abstract

Purpose: The purpose of this paper is to study the importance of retail space for the retailers in the creating a luxury image of handloom brands. This is because locations play an important part in brand positioning. The study can help Indian handlooms sector to position them in the category of luxury brands.

Design/Methodology: The methodological basis of this study is formed by a qualitative approach to data collection. In-depth interviews were conducted with 6 shop owners who had changed their location or recently expanded. The interviewer followed an outline of 7 open ended questions to ensure systematic approach to the research

\section{Objectives:}

a) To identify the areas in Delhi which have a clientele that values Indian luxury items.

b) To identify retailers who have recently changed or expanded their location with respect to these areas.

c) To ask them their experience before changing the location.

d) To ask them their experience after changing the location.

e) To compare both situations and concluding

Findings: The interpretation of the interviews led to formulation of two major thematic areas connecting similarities and differences in the views of the participants. Key areas point the advantage of the location of their present store as compared to their previous store and the factors considered while choosing a space in the market.

Research limitations: The study focuses on the retailers who have their present stores in two areas only i.e. Hauz Khas village and Shahpur Jaat in New Delhi because there is a cluster of Indian designers present there. These are the locations that have the maximum clientele of Indian luxury clothing.

Practical implications: Due to certain constrains the handloom sector is not organized and branded. This study is beneficial for a person or an organisation that has the capacity to collect these exquisite crafts under one umbrella brand.

Keywords: Location; Brands; Luxury; Retailer; Indian handloom; Marketing

\section{Introduction}

India is always been known for its well embellished tradition and culture. The concept of luxury is not new to India. It was acknowledged as the Golden Bird, the land of Maharajas and Nawabs who had sophisticated tastes and were experts of luxury. The notion of luxury is still very prominent in India and we find examples of luxury being connected to Indians almost every day. Be it the grand mansion of the Ambanis' or the most expensive piece of jewellery ever made by the house of Cartier for Maharaja Bhupinder Singh, all signify the connection of luxury to Indian lifestyle [1].
In 2009, market for luxury items in India was estimated to approximately worth USD 4.76 billion and is increasing at the rate of $22 \%$ every year [2]. "India's luxury market is set to grow to USD 30 billion from USD 23.8 billion by the year-end on back of growing exposure of international brands amongst Indian youth and higher purchasing power of the upper class in tier II and III cities, Assocham said today" (Economic Times, 28 February, 2018). This rapid growth is expected because of a relatively young and impressionable society that is becoming exposed to the western 
culture and having high level of disposable income. There are several International brands available in India at present. Some of the examples are Louis Vuitton, Gucci, Giorgio Armani, Chanel etc. With luxury malls in Delhi, Mumbai and Bangalore, international luxury brands are now more accessible [3].

India's passage to modernity and westernization centred on luxury buying has pushed the popularity of Indian luxury handlooms to the background [4]. The affluent consumer who has been consuming "luxury items" for several decades and goes for finer things in life is the consumer of rich traditional handlooms. However, badge conscious aspirant consumer still aspires for international brands only for luxury buying.

India offers a rich tradition of handlooms and each region specializes in different art forms. The handlooms are made by master artisans and each artisan community comes from a long lineage of master artisans who have handed down these traditions to the next generation. Today, however, many of these communities do not want their children to even learn their craft, as there is no scope for steady income from practicing the craft. The main reason for this is that this sector is lacking with infrastructure and communication facilities [5].

In this study, a qualitative methodological framework is used to explore how traditional handlooms can be positioned as "luxury items" by choosing the right retail space. The primary purpose is to establish whether retail space is an important factor in creation of a luxury brand. Presently, the handloom sector does not have a specific retail environment through which they operate. They are available in their respective states' handloom council. The consumers must approach the artisans directly for purchasing of these valuable pieces [6].

\section{Literature review}

The right location for luxury brands: Location of the store is the most significant ' $\mathrm{P}$ '1 in retailing as a retailer can make adjustments in his merchandise mix, marketing communication, services and prices but it is reasonably difficult to change the location [7]. It was once considered that if the store location is right, the store would surely be successful.

Luxury retailing indicates high profile, planed locations within close vicinity of high-income clusters. The expectations of luxury consumers are right mixture of comfort, receptiveness and satisfaction while visiting the store. Accessible parking is expected. Along with appropriate location, the shopping experience expected by the consumer is proper space and right ambiance. All the components of the store must be highly aesthetic, prestigious and creative [8]. The ideal luxury shopping destinations across the word are high fashion streets like that of New York's Fifth Avenue and fashion streets of London [9].

Present scenario of luxury destinations in India: Earlier people had to travel abroad to buy Dior or an Armani. But now we are observing a flood of luxury brands making their way through the Indian market changing the whole scenario. Today, international brands are very accessible hence accounting for the dramatic transformation of luxury retailing. There are more international brands that are looking forward to either establish or expand their operations in India [10].

There are 30 cities in India with a population of one million and 13 cities with more than two million inhabitants. Yet Luxury brands have restricted their presence to three main metros of the country i.e. Delhi, Mumbai and Bangalore [11].

In India, shopping arcades in five-star hotels e.g. Grand Hyatt, Oberoi Trident, Taj Mahal Palace etc act as an appropriate location for luxury retailing. Also, the luxury malls give the right kind of experience to a certain extend [12]. There are only two fully established luxury malls that are operational- UB City in Bangalore and DLF Emporio in Delhi. If we take the example of Delhi, consumers buy luxury products from places like Hauz khas, Shahpur Jaat, Khan Market and Connaught Place [9]. But these places are confined to Indian designer brands only.

The importance of right location for luxury brands: One of the main reasons of international brands not expanding in India is the stringency of suitable retail spaces. If we believe the experts, there is a dearth appropriate retail space keeping many luxury brands away from the country [11]. Out of the total strength of luxury brands, 90 percent are concentrated to malls, the main being DLF Emporio opened in 2008 in Delhi. "There is a serious need to have more retail spaces for luxury brands to expand in India" AT Kearney Principal Neelesh Hundekari. The major gap is the absence of a street that can be addressed as a high fashion street like New York's Fifth Avenue. According to Jean- Christophe Babin, president and CEO of Tag Heuer, Business Line, December 11, 2008, the biggest challenge that they are facing is obtaining an appropriate retail space. There would be a growth in luxury segment with opening of new malls in the country [13].

Due to the inadequacy of proper space, the format of retail gets compromised, hence there is less opportunity for retailers to do good business. They cannot create the overall atmosphere of the store that they would ideally wish to in cooperate. Even if the consumer has the access to all the brands, the shopping experience is still absent somewhere because of the space inadequacy. "We should develop places such as Connaught Place in New Delhi and Colaba in Mumbai, which are landmark heritage shopping districts, into luxury high streets just as Milan, Paris, London, New York, etc., have developed their prime shopping areas into luxury market spaces," Sanjay Kapoor, managing director, Genesis Luxury Fashion Pvt. Ltd, said by email. This is a good point of view of not limiting international "luxury items" to five stars and making it accessible. French luxury brand Hermes has followed the same. It is going to open an independent store at a heritage building in south Mumbai next year [14].

${ }^{1}$ Marketing decisions generally fall into 4 controllable categories which are called the 4 P's i.e. Product, Price, Place and Promotion 
Hence concluding that retail space is the most important aspect that the international luxury brands consider when they plan to establish or expand.

\section{Research Methodology}

The methodological basis of this study is formed by a qualitative approach to data collection. In-depth interviews were conducted with 6 shop owners who had changed their location or recently expanded. Their shop was minimum 2 years old. The areas covered for the study were Hauz khas village and Shahpur Jaat in New Delhi as they have a cluster of Indian designers. The interviews were taken in their facilities for minimum of 20 minutes. The participants were contacted on site to take interviews on the spot. To ensure systematic approach to the research, an outline of 7 open ended questions were followed by the interviewer. Each interview began with the participant reflecting on the present scenario of the luxury market in India. Participants were also invited to discuss their views about Indian handloom sector.

Interviews were conducted with small number of participants until responses reached saturation and there was a repetition noted in the responses $[15,16]$. The interviews were then transcribed with development of notions followed by the interpretive analysis [17]. The interpretation of the responses led to two thematic areas.

a) Advantage of the location of their present store as compared to their previous store.

b) Factors considered while choosing a space in the market.

Within these themes, the common and the different views of the respondents were explored. Key issues within these themes were noted to study what is the impact of the right retail space for the Indian luxury retailers.

\section{Interpretation}

Advantage of the location of their present store as compared to their previous store:At the beginning, the participants were asked to describe the location of their previous store and to reflect on their previous experience describing the factors that led them to change their location. This discussion automatically led to discussing the advantages of their present location.

Two of the participants were located previously in Hauz khas village shifted to Shahpur Jaat and two were located previously in Shahpur Jaat shifted to Hauz khas village. One of the participants shifted from Select City Walk to Hauz Khas and the remaining one participant shifted to Hauz Khas village from Greater Kailash.

On asking their reasons of changing and their experiences with the previous store, one of the reasons that came up was the sealing drive by the municipal corporation that happened in 2008 Other reason was high rentals of the mall that did not lead to any profit and lack of serious buyers. Vaani who had her previous store in Shahpur Jaat and is presently there in Hauz Khas village shares: Shahpur Jaat is less organised and very dirty. It is more of a manufacturing hub. Niche clientele want a very good environment for shopping and that was absent in Shahpur Jaat.

The two participants who shifted from Hauz Khas village to Shahpur Jaat had their own reasons for doing so. Manish, who has his brand Antardesi in Shahpur Jaat now, described: Hauz Village has become a place where people come more for eating and having fun. We wanted some serious shoppers. Hauz khas is preferred and is a good place for artists. It has a good strength of clientele who are art lovers. We are being an apparel brand saw good prospects in Shahpur Jaat.

Mani who has a brand called Amyra had her manufacturing facility in Shahpur Jaat, preferred shifting there when it became a shopping destination. Participants were proud to discuss the advantages of their present location. According to Gazhal who has her present store in Hauz Khas, it is good to be amongst the designer fraternity where she automatically gets a positioning of designer wear and uniqueness for her brand. As Vaani explains: The main factor in retailing of luxury wear is the address. It is good to hand over a business card that has Hauz Khas village as the address. Not everyone comes to shop here. This place is marketed so well when it comes to designer wear. The marketing is not by advertisements but there are media coverage like NDTV good times and lonely planet on discovery. Not only Indians but this place is very popular among foreigners and hence it brings a lot of X-pat crowd here.

Almost all the participants in Hauz khas considered foot fall of NRI's and foreign tourist as an advantage. This was a common factor that was taken as an advantage for participants who had their present stores in Shahpur Jaat also. According to Mani, she has a unique selling point of being in western wear in Shahpur Jaat. But for Manish who has a lot of his competitors there, the advantages were: Those who come here, knows what Shahpur Jaat all is about. Because of the absence of entertainment facilities like eating joints here, people come here to do some serious shopping only and you are sure about the foot fall conversion rates. The low rentals and manufacturing facilities in close vicinity are added advantages. We get bulk orders here which we never had in Hauz Khas village.

When the participants were asked whether their recent location was their first choice, almost all agreed. Manish had Emporio Mall as his first choice. The reason that he gave for not being there was: Established brands are only allowed to have a shop in Emporio. They count the number of fashion weeks, you have been a part of and the amount that you spent advertising in magazines. So we did not qualify.

Factors considered while choosing a space in the market: The participants were asked to describe the factors they considered while placing their store in that market and what part do the location of their competitors play in the placement decision of their shops.

For almost all the participants in Hauz Khas, visibility was the main factor that they considered while deciding the placement of 
their store. Two of the participants in Hauz Khas did not have a choice of location so they had to settle down with what they got. For placement factors in Shahpur Jaat, Manish said: There are a lot of options in Shahpur Jaat, but you cannot place your shop anywhere. There are only two galis here which are the best place by the consumer. Rest of Shahpur Jaat is a manufacturing area.

Mani also agreed for the same factor but for her the first factor that she had in her mind was that she wanted a ground floor which again implies better visibility. All the participants wanted to be around their competitors. Sumit in Hauz Khas say: Keep your friends close and enemies' closer is the phrase that works best here. Staying close to my competitors keeps me updated of the developments that are happening at their end. If you are a designer brand you cannot have your shop near Nike, Adidas. You must be placed with people who are like you and my brand is not so well known that I place my shop in a deserted area. I cannot expect people coming especially for me.
According to Gazhal, she gets an advantage of the spill over clientele from Ogaan, which is an established brand in Hauz Khas. She takes an advantage of the people comparing her merchandise and they end up buying from her shop. Even the participants from Shahpur Jaat considered being good around the competition. Since Amyra has both western and Indian wear, it becomes an advantage. People come to them because of the area being a market for Indian Wear and end up buying westerns as well.

At the end of the interview, the participants were asked to share the new location of their store was beneficial for them. All the participants agreed to the fact that the present location of the store had resulted in better brand identity and sales.

\section{Key findings}

Due to the varied nature of the responses, the findings of the above interpretation can be summarised in a form of a table (Figure 1) which can be divided under four major headers.

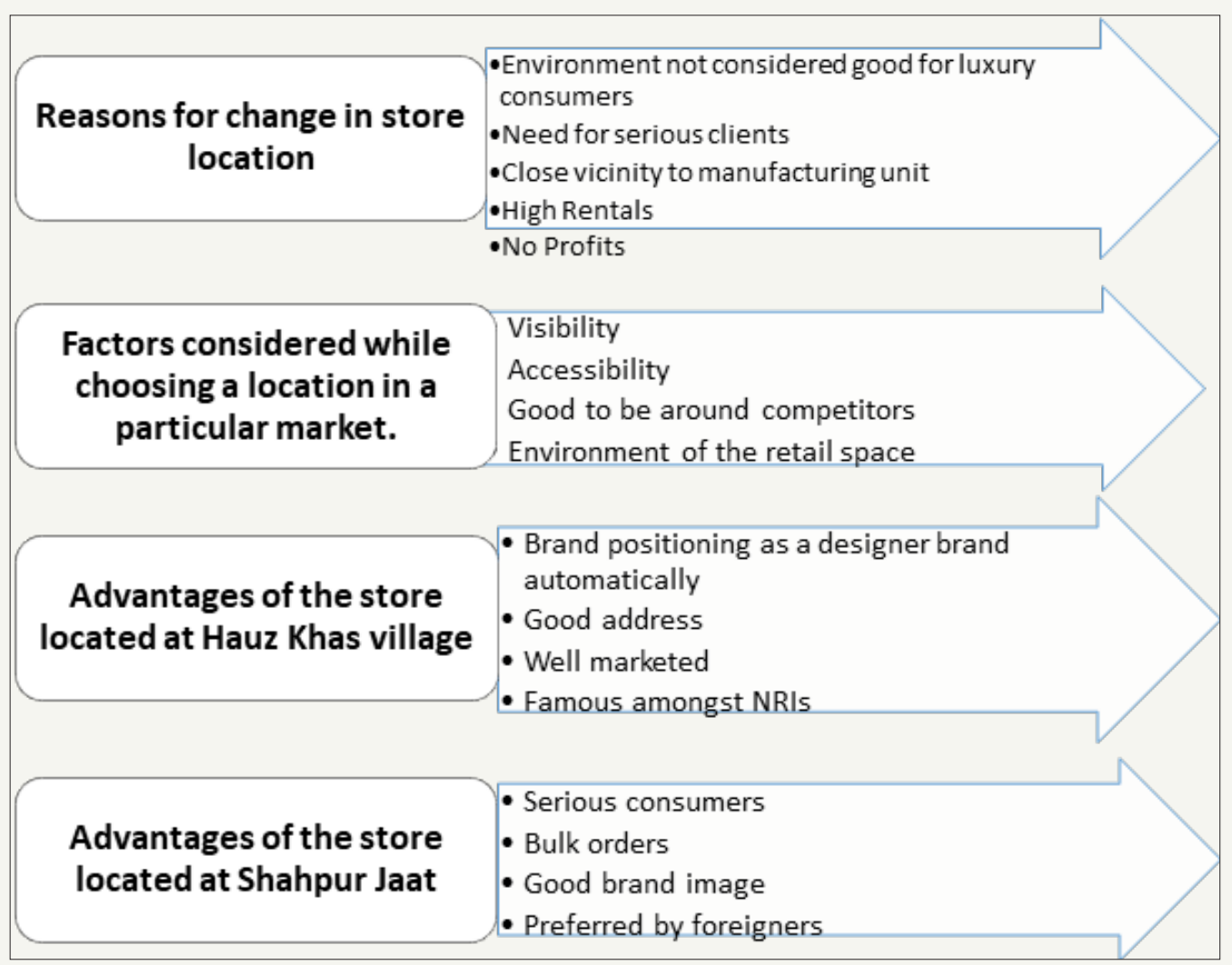

Figure 1: Advantages of the present locations of the participants and the factors considered while choosing a store location.

\section{Conclusion and Suggested Implications}

The goal of this study was to explore that what is the importance of retail space for luxury retailing so that Indian handlooms can position themselves as a "luxury items". The observations of the major themes establish the importance of location. Major chunk of retailing of the handloom sector is done directly by workers who make to order $[6,18]$. They have limited producing capacities which are booked. It is very difficult for these workers to brand their products placing them at the right retail space. This study is beneficial for a person or an organisation that has the capacity to collect these exquisite crafts under one umbrella brand.

The point is that this sector needs to create the appropriate infrastructure for retail since it simply does not exist in the very locations that make sense for luxury retail. This study covers the retailers of ethnic wear in two areas of Delhi. The stores in these areas offer exquisite Indian designs. These designs include a lot 
of handwork which makes them valuable but the stores in these areas do not offer traditional Indian handlooms fabrics that are the ultimate luxury and desired by few [19]. People who are currently buying these items directly from the weavers may not choose Hauz Khas or Shahpur Jaat to buy these crafts. But these areas can be taken as examples as they have created a proper infrastructure and retail environment for their target consumers. The Indian handloom sector needs to reposition itself and for that repositioning, they must build a similar retail environment where there are a cluster of retailers serving to the consumer. If this retail environment is established, the crafts will be recognized and hence will become aspiration items.

Luxury Malls in India can serve a good retail environment for these items. One of the findings of the study is that the luxury malls present in India have an entry barrier. These barriers can be overcome by help of government as these crafts are always promoted [10]. Also, there are several Indian designers already present in these malls who can start up a new line with these exquisite pieces [15].

Much more research is required to understand the consumer behaviour towards these products. But the need of the hour is to provide a suitable platform to these artists so that the art is carried through the generations to come and not get confined to the books that discuss history of fashion.

\section{References}

1. Mishra J (2010) The state and scope of luxury retailing in India. Fiber to Fashion.

2. Keanery AT (2010) Luxury in India. Charming the Snakes and Scaling the Ladders. confederation of Indian Industry, New Delhi, India
3. Times of India (2018) India's luxury market to cross $\$ 30$ bn by year-end: Assocham.

4. Dutta S (2010) Preserving Indian handicrafts.

5. Rasch J (2011) Buy handicrafts to preserve the arts of India. Shopping and product reviews: Fashion style.

6. Shrivastava P (2010) Indian handicrafts industry SWOT analysis.

7. Waters S (2017) Choosing a retail store location, important location factors when opening a store.

8. Mayuri (2010) Vendome woollahra to bring luxury brands under one roof

9. Dutt S (2011) Indian luxury retail-high street troubles. Indian Express.

10. Malhotra N (2010) India, a favoured destination of luxury retail.

11. Ridge M (2010) Report touts luxe potential for India. WWD, New York, USA, 199(71): 12.

12. Anonymous (2010) India's DLF plans more luxury malls, eyes Hyderabad, Chennai, Asia Pulse.

13. Anonymous (2008) Catalyst- in luxury consensus means failure, Tag Heuer. Financial Times Information Limited - Asia Africa Intelligence Wire.

14. Anonymous (2010) Luxury retail looks beyond metros and malls. p. 6.

15. Kvale S (1996) Inter-views. Sage Publications, Thousand Oaks, CA, USA.

16. McCracken G (1988) The long interview. Newbury Park, CA, USA.

17. Spiggle S (1994) Analysis and interpretation of qualitative data in consumer research. Journal of consumer research 21(3): 491-501.

18. Patel U (2011) Discussion on the present scenario of Indian luxury handlooms and the consumer of Indian handcrafted luxury, Interview.

19. Anonymous (2010) India's luxury market likely to touch US $\$ 14.7$ by 2015: Report, Asia Pulse.
Creative Commons Attribution 4.0

International License

For possible submissions Click Here

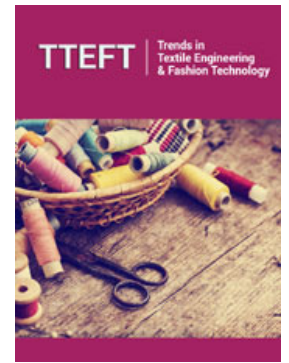

Trends in Textile Engineering \& Fashion Technology

\section{Benefits of Publishing with us}

- High-level peer review and editorial services

- Freely accessible online immediately upon publication

- Authors retain the copyright to their work

- Licensing it under a Creative Commons license

- Visibility through different online platforms 